The Korean Journal of Parasitology

Vol. 41, No. 2. 97-100, June 2003

Case Report

\title{
A case of acute gastric anisakiasis provoking severe clinical problems by multiple infection
}

\author{
Ji Hun $\mathrm{NOH}^{2)}$, Bong-Jin $\mathrm{KIM}^{1)}$, Sun Mee KIM${ }^{1)}$, Mee-Sun $\mathrm{OCK}^{1) *}$, Moo In PARK ${ }^{2)}$ and Ja Young GOO ${ }^{2)}$ \\ ${ }^{1)}$ Department of Parasitology, ${ }^{2)}$ Department of Internal Medicine, Kosin Medical College Busan 602-703, Korea
}

\begin{abstract}
Acute gastric anisakiasis with multiple anisakid larvae infection is reported. A 68-year-old woman residing in Busan, Korea, had epigastric pain with severe vomiting about 5 hours after eating raw anchovies. Four nematode larvae penetrating the gastric mucosae in the great curvature of the middle body and fundus were found and removed during gasteroendoscopic examination. Another one thread-like moving larva was found in the great curvature of upper body on the following day. On the basis of their morphology, the worms were identified as the 3rd stage larvae of Anisakis simplex. This case is acute gastric anisakiasis provoking severe clinical problems by the multiple infection and the greatest number of anisakid larvae found in a patient in Korea.
\end{abstract}

Key words: Anisakis simplex, gastric anisakiasis, fish

Anisakiasis is one of the fish-transmitted infection that results from accidental ingestion of third-stage larvae belonging to the family Anisakidae. Human infection can occur by consumption of raw or undercooked fish, such as mackerel, squid, cod, anchovy, salmon and tuna. These fishes act as an intermediate host for ascarids of sea mammals. About two thirds of people who eat these fishes harboring larva experienced gastric or intestinal symptoms, including epigastric pain, nausea, vomiting and etc., two to six hours afterwards (Sugimachi et al., 1985). Many reports have been issued on gastric and intestinal anisakiasis in Korea (Im et al., 1990, 1995) and elsewhere (Muraoka et al., 1996; Lopez-Serrano et al. 2000), but most of the cases have involved a single worm infection (Kim et al., 1991). Although, Seol et al. (1994) reported upon the removal of twenty-two

- Received 27 January 2003, accepted after revision 27 May 2003.

*Corresponding author (e-mail: msock@ns.kosinmed.or.kr) worms from 20 Korean patients, they did not specify the number of worms collected from each patient. We have experienced a case of multiple infection of anisakid larvae in one patient.

A 68-year-old Korean woman, residing in Busan, Korea, was admitted to the emergency room at Kosin University Hospital in May 12, 2002. About one hour after eating raw anchovies in thick soypaste mixed with red peppers, the patient showed symptoms of vomiting and epigastric pain. When admitted to the hospital five hours after eating the anchovy, she complained of severe epigastric pain, chest pain and vomiting, and then immediately fell into a state of mental stupor. A total blood count, chemical examination of blood and urinalysis, and EKG were normal. A gastroendoscopic examination was done on May 13, 2002 (19 hours admission), and four threadlike worms were found penetrating the gastric mucosa in the great curvature of the middle body and fundus (Figs. 1A to 1D). Another one long-white 


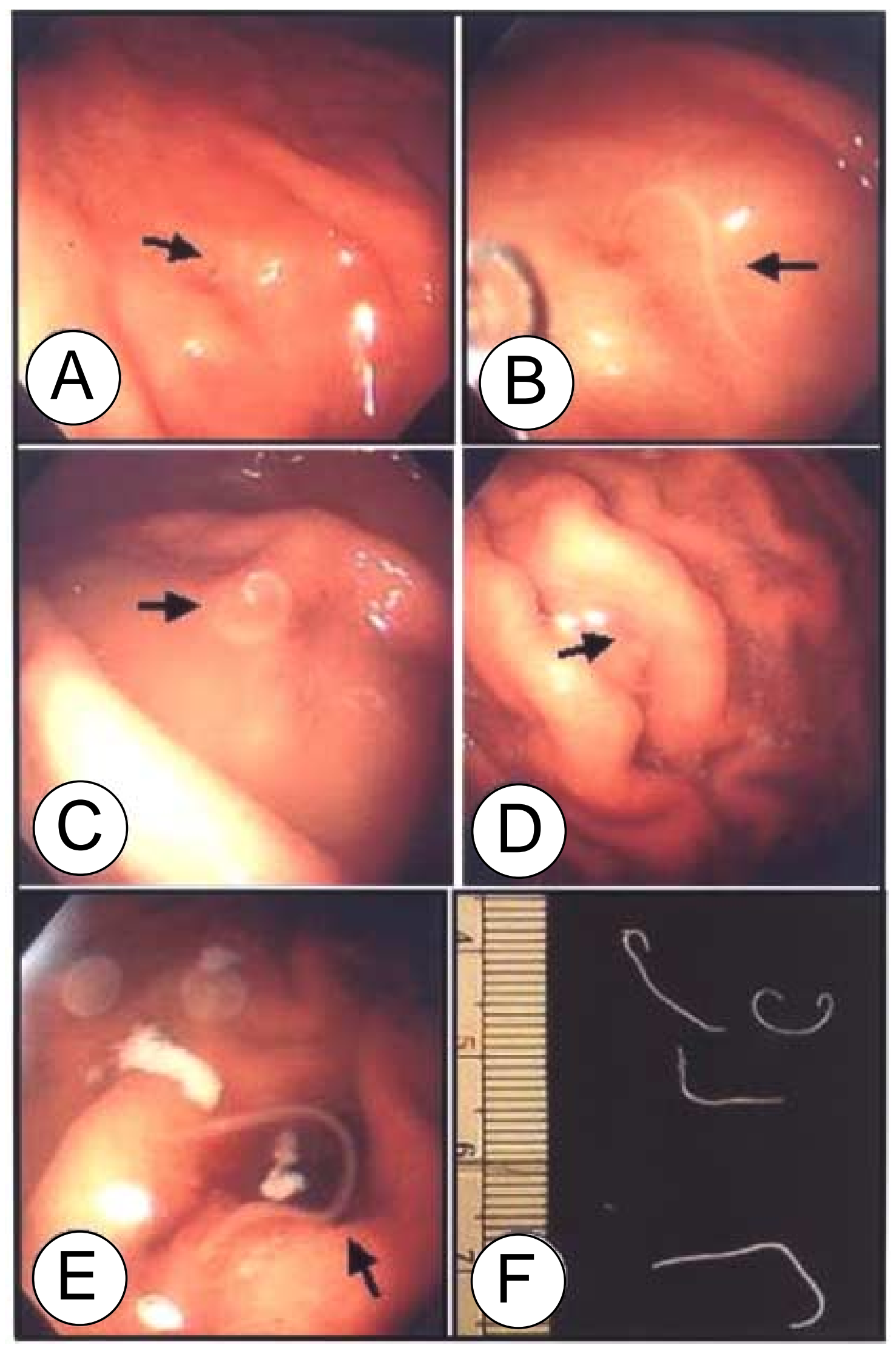

Fig. 1. Anisakid larvae observed by gastroendoscopic finding. Pictures A from $D$ are taken at the first day examination, E was 2nd day's photo. F: four Larvae extracted from stomach of patient by gastroendoscopy. 
Table 1. Measurements ${ }^{\mathrm{a}}$ and indices of Anisakis type I larvae in comparison with the results of Chai et al. (1986)

\begin{tabular}{|c|c|c|c|c|c|}
\hline \multirow{2}{*}{ Items } & \multicolumn{4}{|c|}{ Present study (average) } & \multirow{2}{*}{ Chai et al. (1986) } \\
\hline & larva 1 & 2 & 3 & 4 & \\
\hline Body length (L) & 16.5 & 17.5 & 19.5 & $28.1(20.4)$ & $13.4-25.0(20.7)$ \\
\hline Body width (W) & 0.3 & 0.3 & 0.4 & $0.5(0.38)$ & $0.23-\quad 0.54(\quad 0.41)$ \\
\hline Esophagus (E) & 2.57 & 3.33 & 2.42 & $3.55(2.97)$ & $1.86-2.70(2.36)$ \\
\hline Muscular part (M) & 1.93 & 2.30 & 1.50 & $2.60(2.08)$ & $1.27-1.89(1.65)$ \\
\hline Ventricular part (V) & 0.64 & 1.03 & 0.92 & $0.95(0.89)$ & $0.57-\quad 0.83(\quad 0.71)$ \\
\hline Tail (T) & 0.12 & 0.11 & 0.10 & $0.13(0.12)$ & $0.07-\quad 0.12(\quad 0.10)$ \\
\hline$\alpha(\mathrm{L} / \mathrm{W})$ & 55.0 & 58.3 & 48.8 & $56.0(54.5)$ & $43.7-66.3(50.6)$ \\
\hline$\beta_{1}(\mathrm{~L} / \mathrm{E})$ & 6.42 & 5.26 & 8.06 & $7.90(6.91)$ & $7.02-9.92(8.73)$ \\
\hline$\beta_{2}(\mathrm{~L} / \mathrm{M})$ & 8.55 & 7.61 & 13.0 & $10.8(9.99)$ & $10.01-14.70(12.5)$ \\
\hline$\beta_{3}(\mathrm{~L} / \mathrm{V})$ & 25.8 & 17.0 & 21.2 & $29.6(23.4)$ & $25.5-39.4 \quad(29.2)$ \\
\hline$\gamma(\mathrm{L} / \mathrm{T})$ & 137.5 & 159.1 & 195.0 & $216.2(177.0)$ & $167.6-271.3 \quad(213.4)$ \\
\hline
\end{tabular}

a) unit is $\mathrm{mm}$.

nematode was found at the great curvature side of upper body during an endoscopic examination performed on the following day (Fig. 1E). The gastric mucosa of the body and antrum showed diffuse hyperemia. No more worms could be found during a third endoscopic examination carried out on two days after the initial examination. The state of patient improved immediately after removing the worms and she was discharged after receiving supportive care on 17 May 2002.

The worms were fixed in 10\% formalin, cleared in glycerin-alcohol, mounted with glycerin-jelly and observed under a light microscope equipped with a micrometer. The length and maximum- width of the worms were as follows; $16.5 \times 0.3 \mathrm{~mm}, 28.1 \times 0.5 \mathrm{~mm}$, $19.5 \times 0.4 \mathrm{~mm}$, and $17.5 \times 0.3 \mathrm{~mm}$ (Fig. 1F). The fifth worm extracted from the second endoscopic examination was not secured. The third-stage larvae usually have average length of $20.0-30.0 \mathrm{~mm}$, and slender esophagus is followed by ventriculus which forms an oblique junction at the posterior end with the intestine. The larvae have lips at the anterior end and a mucron at the posterior end. The worms of this report had mouths equipped with three lip bulges and boring teeth, a mucron at the posterior part. We were unable to find an intestinal cecum. The measurements and indices of the present specimens (Table 1) also represent common characteristics and morphological features of the third-stage larvae of Anisakis simplex. On the basis of the morphology and measurements, the parasites were identified as the third-stage larvae of Anisakis simplex.

Four species of anisakid are known, i.e. A. simplex type I and type II, and a Pseudoterranova type A and Contracaecum sp. Most anisakiasis, however, take place by the larva of Anisakis simplex. The main sources of anisakid infection in Korea are, cuttle-fish, yellow corvina, sea eel, ling, and yellowtail (Im et al., 1995). Song et al. (1995) reported that the muscle of anchovy is highly infected with anisakid larvae. Moreover, their report (Song et al., 1995) suggests that human infection is possible from the consumption of anchovy. This case confirms that anchovies can cause anisakiasis. Most reports on anisakiasis indicate that the most frequent parasitic location is in the great curvature of the lower, mid and upper body. In the present case worms were also distributed over the great curvature of the fundus, the middle body and the upper body. The reason why the worms are recovered primarily from the great curvature is not clear. Shibata et al. (1989) noted that the great curvature provides a good environment for anisakid larvae for penetrating the gastric wall, due to the large number of folds and the more active secretion of mucus in this region.

Although Choi et al. (1989) reported finding two larvae in one patient among five anisakiasis cases in Korea, almost all anisakiasis cases have recorded single worm removal in one patient. We found four larvae during the first gastroendoscopic examination and another one in a second examination. The patient in this case experienced typical gastric anisakiasis 
symptoms and fell into mentor stupor by the intolerable epigastric pain. Therefore, we recommend that multiple anisakid larval infection should be borne in mind.

\section{REFERENCES}

Chai JY, Chu YM, Shon WM, et al. (1986) Larval anisakids collected from the Yellow Corvina in Korea. Korean J Parasitol 24: 1-11.

Choi SH, Ahn BM, Kim JK, et al. (1989) Five cases of acute gastric anisakiasis. Korean J Gastroenterol 21: 593-599.

Im KI, Yong TS, Shin HJ, et al. (1990) Gastric anisakiasis in Korea - with review of 47 cases. Yonsei Rep Trop Med 21: 1-7.

Im KI, Shin HJ, Kim BH, Moon SI (1995) Gastric anisakiasis cases in Cheju-do, Korea. Korean J Parasitol 33: 179-186.

Kim SE, Kim SL, Lee KS, et al. (1991) 9 cases of acute gastric anisakiasis. Korean J Gastroenterol 23: 866-872.

Lopez-Serrano MC, Gomez AA, Daschner A, et al. (2000)
Gastroallergic anisakiasis: Finding in 22 patients. J Gastroenterol Hepatol 15: 503-506.

Muraoka A, Suehiro I, Fujii M, et al. (1996) Acute gastric anisakiasis: 28 cases during the last 10 years. Dig Dis Sci 41: 2362-2365.

Seol SY, Ok SC, Pyo JS, et al. (1994) Twenty cases of gastric anisakiasis caused by Anisakis type I larva. Korean J Gastroenterol 26: 17-24.

Shibata O, Uchida Y, Furusawa T (1989) Acute gastric anisakiasis with special analysis of the location of the worms penetrating the gastric mucosa. Gastric anisakiasis in Japan. Epidemiology, Diagnosis, Treatment. Ishikura H, Manik M eds., pp 53-57, Springer-Verlag, Tokyo, Japan.

Song SB, Lee SR, Chung HH, Han NS (1995) Infection status of anisakid larvae in anchovies purchased from local fishery market near southern and eastern sea in Korea. Korean J Parasitol 33: 95-99.

Sugimachi K, Inokuchi K, Ooiwa T, et al. (1985) Acute gastric anisakiasis. Analysis of 178 cases. JAMA 253: 1012-1013. 